
? DAs

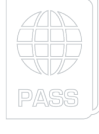

\title{
SUSTAINABLE TOURISM IN SKI RESORTS OF EUROPE AND THE WORLD
}

\author{
Nataša Dragović*, \\ Milana Pašić
}

Faculty of Sciences, University of Novi Sad, Novi Sad, Serbia
Correspondence:

Nataša Dragović

e-mail:

dgt.natasa.dragovic2@student.pmf.uns.ac.rs

\begin{abstract}
:
A specific feature of ski tourism is its dependence on climatic conditions so that activities on snow can be realized. Understanding the impact of tourism developments would help the sustainability of tourism management. Sustainability can be viewed from several aspects, the two most often considered being economic and environmental sustainability. This paper presents an overview of sustainable practices in ski resorts in Europe and the world. The aim is to present sustainable practices and to compare different ways of solving the problem of climate change, i.e. the application of adaptation strategies. Ski resorts differ in terms of resources, altitude, and geographical location. Thus, different sustainable practices are needed. The main problems that disrupt the sustainability of the destination are the emission of carbon dioxide (CO2) into the atmosphere as a consequence of mass tourism movements in the form of transport to the mountain and on the mountain, then insufficient snow at lower altitudes during the winter months. Also, deforestation, changing landscapes and disrupting the functioning of ecosystems due to the need to develop ski resorts in the form of infrastructure projects. A sustainable way of managing ski resorts should enable the smooth flow of the winter tourism season, without disturbing the ecosystem and the natural environment.
\end{abstract}

\section{Keywords:}

sustainable development, environmental sustainability, ski resorts, climate changes.

\section{INTRODUCTION}

Sustainable tourism has been studied for years, with so many definitions, tools, strategies, and principles having been developed. Some of them are 1995 Charter for Sustainable Tourism, the Berlin Declaration: Biodiversity and Sustainable Tourism of 1997, the Johannesburg Implementation Plan: Sustainable Tourism of 1992, the Global Codes of Ethics for Tourism of 1999, the Quebec Declaration on Ecotourism of 2002, Cape Town Declaration: Responsible Tourism in Destinations from 2002 (Ecological Tourism in Europe, 2005). The scientific literature that studies tourism is increasingly dealing with environmental issues and harmful effects of tourism on the environment. Tourism development is not only going in an unsustainable direction, but is becoming unsustainable globally which may be a problem in the future 
(Buckley, 2012; Gössling et al., 2012; Hall, 2011; Peeters, 2012; Peeters and Dubois, 2010; Scott et al., 2010; Weaver, 2009; Rutty et al., 2014). The effects of climate change on tourism are also great, and how tourism responds to these changes is of great importance for sustainable tourism (Scott, 2011).

The World Tourism Organization has defined development of sustainable tourism as such that it should meet the needs of tourists and hosts in a way that will increase opportunities for future development. Sustainable tourism should manage available resources without compromising the environment, biodiversity, environmental processes, and cultural integrity while meeting economic and social needs (United Nations World Tourism Organization, 1998). The involvement of all actors in tourism can achieve sustainable tourism development. These are stakeholders, each of whom has a role in tourism - local communities, hoteliers, restaurateurs, tour guides, tour operators, travel agencies, tourism organizations, NGOs, media, scientific institutions, etc. For their activities to be sustainable, they need to be involved in the planning process from the very beginning. This includes cooperation, exchange of information, and consultation in decision-making on activities that follow the sustainable development of tourism (Ecological Tourism in Europe, 2005). There are many definitions in the literature, but most of the scientific community dealing with sustainable tourism believes that sustainability should reduce the impact on the environment, close the consumption cycle to eliminate as much as possible non-economical production and reduce unnecessary investments (Epstein, 1996; McDonough and Braungart, 2002; Smerecnik and Andersen, 2011). Implementing the concept of sustainable tourism can have different results. According to some literature, there are positive effects of the concept of sustainability on visitor satisfaction (Kassinis and Soteriou, 2003), whereas there are examples when the concept of sustainability did not have concrete evidence of positive impact (Claver-Cortés et al., 2007). In order to achieve the goal of the work, examples of managing ski resorts in a sustainable way in Europe and the world are presented. The subject of the paper is to consider sustainable ski resort management practices in Europe and the world, and to examine whether current practices contain some aspects of sustainability. The task of the paper is to analyse current and future practices for ski resort management, as well as to review examples of good practice.

\section{Sustainable practices in ski resorts}

This chapter will present examples of application and development of sustainability strategies in ski resorts in Europe and the world. Based on these examples, conclusions will be drawn that indicate the problems that ski resorts face, the ways they solve the problems and what are future planned strategies for sustainability.

\section{Examples in Europe}

For ski resorts in Switzerland, a study of climate change and lack of snow during the winter was conducted. It is probable that disturbance in snowfall has risen due to tourism and its impacts thus causing the problem of insufficient snow cover for winter activities such as skiing. It is predicted that Swiss ski resorts need a snow cover height of at least $30-50 \mathrm{~cm}$ in 100 days (a period from December 1 to April 15), in seven to ten winter seasons, so that winter activities can be carried out without problems (Buerki et al., 2003). Out of a total of 230 ski resorts, $85 \%$ should have enough snow during the winter season. The effects of global warming are likely to affect the ski resorts of the Jura, eastern and central Switzerland, the cantons of Ticino, Fribourg, and Vaud. In contrast, the Valais and Grisons regions will not have such problems because the average altitude at which the cable car terminals are located is over $2500 \mathrm{~m}$ above sea level. In the future, the problem may arise at the ski resorts with the average altitude of $1800 \mathrm{~m}$ and less. In that case, only $44 \%$ of ski resorts would have conditions for winter activities. Based on the discussions of the focus groups, strategies for adaptation to climate change was adopted, which include four groups of activities:

1. management of ski tourism by making artificial snow, development of the terrain at higher altitudes, design of ski slopes, and cooperation;

2. subsidies which include annual contributions and one-off contributions;

3. fatalism reflected in the fact that neither consumers nor suppliers change their behaviour, as well as in the fact that ski tourism can be abruptly interrupted, without any announcement activities;

4. alternatives to ski tourism that should not be strictly related to snow and tourism throughout the year (Buerki et al., 2003). 
The working group for sustainable tourism of the Alpine Convention with representatives from Austria, Switzerland, Slovenia, Italy, Germany, Monaco and Liechtenstein wrote a document for the period from 2016 to 2018 entitled: Guidelines for innovation in Alpine tourism destinations. This report covered the current challenges and expected future scenarios for the mentioned destinations. They were assisted in this by tourism, sustainability and destination management experts who represent and implement sustainable practices. Alpine tourism destinations are facing the problem of mass tourism, i.e. the increased number of tourists. The working group concluded that areas should be established to which access to traditional vehicles would not be allowed, but e.g. bicycle rental, electric vehicles, free public transport services, etc. Also, in certain areas the number of people staying there at the same time should be limited, an offer that would schedule the arrival of people at different times of the day should be created, modern technologies such as applications for portable devices applied, and promotion of cooperation with less visited areas should be encouraged, i.e. visitor flow management (Alpine Convention, 2019).

Research by Bonzaniga et al. (2016) focused on the application of the concept of adaptation to climate change in a local discourse on sustainable tourism development. The case study was performed in the Italian Dolomites, Auronzo di Cadore, and Misurina. This research involved the local community and experts with the aim of strengthening winter tourism performance in a sustainable way. The methodological framework "Network Analysis-Creative System Modelling-Decision Support" was used, which was adapted to the needs of this case study using a combination of several tools (NetSyMoD, Giupponi et al., 2006). Primarily, all research participants were interviewed regarding this area, their views and opinions on current and future development, and sustainable tourism. After that, two workshops were held. Three strategies have been defined that differ in terms of use of natural, social, and economic resources, but their common goal is to strengthen winter tourism. Ski-intensive strategy (SKINT-intensive) means a high-tech ski centre with new lifts, hotels, restaurants, and artificial snowmaking facilities. The alternative-skiing strategy (ALTIC) consists of Nordic skiing and free-ride skiing. The "beyond-snow" (BYDSNW) strategy means giving up investing in skiing in favour of a resort based on health and family tourism, with an increase in offer that is not related to snow. According to potential future climate and socio-economic changes, the results show that the desired solution of this region is based on activities away from the snow. The beyond-snow strategy (BYDSNW) may be linked to the local public transport project, as greater needs for tourist transport are foreseen in the future. An alternative skiing strategy could be successfully implemented between the lifts, while a ski-intensive strategy should be avoided as a possible mistake in the medium and long term. Elevator operators are recommended to control the optimization of the existing infrastructure and ancillary services. For Auronzo di Cadore, the focus is on traditional ski families and activities from the "away from the snow" strategy, and for Missouri, the main point of development would be an alternative skiing strategy. Certainly, the mentioned strategies will not be able to develop independently but with the support of the planned sustainable development (Bonzanigo et al., 2016).

The "Seiser Alm" plateau covers an area of $50 \mathrm{~km}^{2}$ and is located between $1700 \mathrm{~m}$ and $2350 \mathrm{~m}$ above sea level. The area is suitable for hiking, skiing, and winter sports and a destination known for a large number of overnight stays - over 350,000 on the plateau and over 1.5 million in neighbouring areas in 2014 (Astat info, 2015). In the face of a large volume of traffic on the road to the plateau, which at the same time has a very bad impact on the environment, individual transport was closed from 9 am to $5 \mathrm{pm}$ with exceptions for accommodation. Alternative access was provided by cable car. This idea was initiated by actors from the tourism sector, and later this initiative was supported by the local community. Until the realization of the idea, there were many obstacles, mostly by the local population who could not accept that access to the plateau was no longer free. This problem has been resolved with more favourable maps for the local population. Today, they are satisfied because the number of people moving on the roads has really decreased. An important result of this project is the reduction of CO2 emissions by 2100 tons per year (Arge Alp, 2015). Also, places that were not previously accessible are now developed winter destinations (Scuttari et al., 2016).

The mentioned working group also created a brochure of examples of sustainable Alpine destinations. Most of them have well-developed ski centres that implement ecological practices. In France, it is Chamonix, mainly oriented towards winter sports activities, where winter tourism accounts for $53 \%$ of annual visits. This region includes four municipalities, and their priority is sustainable movement through the region, reducing $\mathrm{CO} 2$ emissions, which is in line with the Territorial Plan of Energy Clusters and the Atmospheric Protection Plan. 
Activities include renovation and improvement of the railway infrastructure, a renovated bus line with Euro 6 standard vehicles, six hybrid buses, two small $100 \%$ electric buses. For the flow of tourists to be unhindered, the timetables are adjusted to the seasons and the frequency of movement, that is. during the winter there are more train lines than in the summer (Alpine Convention, 2019).

Cortina in Italy is known for holding the 1956 Winter Olympics. It is one of the most famous ski resorts in Italy, where the winter season starts in November and lasts until April. The Italian Ministry of Environment Protection, together with its partners, has signed the "Cortina Charter", committing itself to nature protection through implementation of environmental practices. This charter is especially important because it is planned for the World Ski Championship in 2021 to be held here. The result of these activities is a reduction in the impact of winter sports activities, an increase in resource efficiency, a reduction in greenhouse gas emissions, and a reduction in energy costs (Alpine Convention, 2019).

Since 1931, Zermatt (Switzerland) has not allowed cars, except in special cases when a license can be obtained for the use of an electric or another vehicle that does not emit harmful gases into the atmosphere. Arrival is possible by shuttle train from neighbouring Tasch, and there are about 500 electric vehicles and several carriages. In this way, they enabled easier movement without crowds, reduced traffic through the promotion of slow movement in the area, noise emission, and air pollution. The city was awarded the "Energiestadt" label for fulfilling $59 \%$ of the measures through innovative techniques and thus maintaining good air quality. It also has a smart waste disposal system and produces $60 \%$ of its energy consumption with hydropower plant (Alpine Convention, 2019).

One million visits a year take place in the city of Saas-Fee, in the north of Switzerland. Like Zermatt, this city has the "Energiestadt" award with $62 \%$ of the measures achieved to receive the recognition of the Gold Standard of the European Energy Award. All pilot studies of the Alpine Convention are being held in this territory. Since the 1980s, the use of cars has been banned, except for public transport by electric vehicles. All electricity is produced from sustainable energy sources and a solar heating system has been introduced. In all wood heating systems, in this area, a filter for dust particles has been introduced to become the first alpine area without fine dust particles (Alpine Convention, 2019).

\section{Examples in the world}

Strategies, knowledge, motivation, and other drivers of all stakeholders in Utah (United States) ski resorts were examined through interviews. Those who manage the sustainability of the ski centres with their activities, either directly or indirectly, participated. The research aims to understand current and future environmental practices. To achieve this, the interviews were designed to get answers to the questions about awareness and application of environmental practices from ski resort managers, to learn the extent to which current environmental practices are effective, and whether there is a need for new improved practices within recent environmentally based managerial activities. Respondents believe that environmental practices are important and valuable for ski resorts, as well as have a positive impact on the environmental development and wealth of the ski and tourism industry. They also state that measures and efforts have been taken to support future environmental development and are aware of the challenges they face, highlighting the financial challenges as they are large financial expenses for the maintenance of ski lifts, ski slopes, and artificial snow. Last, respondents have had a positive perception that their resort would continue with environmental practices in the future and have been open to more intensive cooperation with local communities through the improvement of the existing environmental practices. Visitors who have been interviewed believe that environmental practices are not of great importance for these ski resorts and do not choose a ski resort based on whether environmental practices are implemented in the area or not (Call, 2012).

Training for eco-drivers has long been studied in the literature related to transport. Rutty et al. (2014) researched the Blue Mountain Resort in Ontario (Canada). This site is located within the UNESCO biosphere reserve. This research assesses the relationship between the economic and environmental impacts of a driver's behaviour in a tourist environment. This is one of the ways to improve the sustainability of ski resorts, which results in a measurable reduction of harmful emissions from vehicles. The resort has confirmed the installation of technology or chips "CarChips" for tracking vehicles from their fleet, which will assess the possibility of reducing emissions. The research was conducted from 2009 to 2011 in three parts. 
The first collection of the vehicle, fuel, and emission data, the second behavioural intervention, and the third collection of vehicle, fuel, and emission data after training. According to the results, at idle, the vehicle consumes an average of eight litres of fuel and emits more than $18 \mathrm{~kg}$ of CO2. These are average results because different vehicles were used during the research. When the data are extrapolated, a result is obtained which shows that 55 vehicles at idle consumption consume more than 42,000 l of fuel and emit more than 97 tons of CO2. The usefulness of car tracking technology has proven to be positive in terms of improving sustainability. After the training, the vehicles were monitored again and a decrease in daily $\mathrm{CO} 2$ emissions was observed, the average daily idle fuel consumption and the average daily idling costs were reduced by $8 \%$. The resort has reduced fuel consumption and associated $\mathrm{CO} 2$ emissions. All 14 vehicles that passed the survey showed an improvement, drivers reduced overall daily speed by $-14 \%$, strong decelerations by $-55 \%$, strong accelerations by $-44 \%$, idle by $-2 \%$. Based on this, fuel consumption was reduced by $-8 \%$, and CO2 emissions by $-8 \%$ (Rutty et al., 2014).

Hopkins (2014) researched the Queenstown Lake region (New Zealand), i.e. what is the main strategy for climate change adaptation in a ski resort belonging to the Queenstown municipality and how stakeholders from the tourism industry, municipal representatives, and tourists perceive current climate change adaptation strategies in terms of sustainability? The aim is to assess the sustainability of adaptation to climate change. In response to climate change, the ski industry in Queenstown can have three solutions in addition to making snow: transition to year-round tourism, formation of conglomerate business ventures, and development of slopes or terrain at higher altitudes. After interviews with stakeholders and the local population, it was possible to single out two approaches to tackle the climate change: exploiting the increased vulnerability of the ski industry in Australia and snowmaking technology. Making artificial snow can also be unsustainable, but the positive side is the extension of the ski season and the number of visitors, which increases the income from skiing. Increasingly, snowmaking is defined as a business strategy aimed at economic sustainability, and adaptation to climate change should also be environmentally sustainable. In this research, the spectrum of demand perception was identified. Differences in perceptions can be explained by the level of skiing skills, type of skiing and age, as well as worldview and social needs. The differences between the participants in the research, i.e. there are moral and ethical conflicts regarding skiing, snowmaking, environmental sustainability, and resource consumption. Sustainable tourism in Queenstown, and the whole of New Zealand, requires more attention. Strategies that would be sustainable must include strategies for adapting to climate change and resource consumption. To address unsustainable strategies, organizational structures and intentions need to be considered. This study also showed results that show a discrepancy between different types of skiers, i.e. skiers on the piste are more willing to accept the technology of making snow, unlike skiers off the piste (Hopkins, 2014).

There are 12 commercial ski resorts in New Zealand, and some of them share information and communicate about environment issues on their website. It is a process of disseminating information and implementing communication practices related to the environment. The ski resorts included in the research are Coronet Peak, The Remarkables, Mt Hutt, Ohau, Porters. Data collection was performed in three ways: annexation of managers who have a significant role in communications with the environment, interviewing skiers, and collection of all communications with the environment that met the conditions of possible production at the mentioned ski resorts. Other individuals who play significant roles in creating or disseminating communications with the environment are also considered. The results of the research were divided into four groups. The first group included conclusions and discussions about how the transport of skiers manifested itself in communication with the environment and how managers and skiers perceived it. The second group analysed the ability of ski areas to use communication with the environment to build legitimacy without solving the problem of transporting skiers. The third considered the lack and implications of "green fatigue", identified in this study, on social legitimacy. The last one considered how these dynamics affected the prospects of ski area expansion plans and the role of such developments in fostering additional transport-related emissions. The first group gave results that showed that the respondents were not so aware of climate change, but that they felt that the environment was in some way disturbed and endangered. Also, it could be concluded that ski area managers had responsibility only for the local environment and that transport was outside their jurisdiction. For example, representatives of the Ohau ski resort stated that people crossed half of the world to come to New Zealand, thus they would have to be transported by a certain means of transport, thus already causing the emission of harmful gases. However, there is no public transport to the Ohau ski area, and they do not promote active driving. What is represented is the measurement of harmful gas emissions, but not caused by transport, but by the operation of the ski resort. 
The second group of results showed that respondents were aware of the vulnerability of the environment and therefore pointed out that publishing information about communication with the environment affected employees in organizations by publicly showing their views and perspectives on the environment. Also, they did not want to show in any way that they did not respect nature and believed that their activities were in accordance with sustainable principles. The third group of results showed that there was a lack of "green fatigue" among skiers, i.e. that skiers did not often have the opportunity to see environmental messages and the like, while ski managers said that skiers viewed the ski resorts themselves as ecological. Therefore, skiers were not particularly critical of ski resorts and their approaches to environmental communication. Ski area managers believed that the lack of "green fatigue" among skiers stemmed from three factors: New Zealand ski areas have adopted a restrained approach to communication with the environment, their ski industry is smaller than some in neighbouring countries and New Zealand presents itself in an environmentally friendly light. The fourth group of results showed that the managers of the Ohau ski resort recognized in their guests that they loved the wilderness that surrounded their ski resort and that was why they come. In interviews, skiers expressed awareness of the impacts that could result from expanding the ski area, but most were in favour of preferring larger ski areas with additional terrain and better infrastructure. Those who were against the expansion of the ski area pointed out environmental reasons such as large crowds, more negative impacts on the environment, and that there is already sufficient infrastructure (Spector, 2017).

\section{DISCUSSION}

The examples in the previous chapters show that ski resorts around the world, regardless of location, size, equipment, number of tourists, have the same problems with climate change and strategies for adapting to these changes, which are in line with the sustainability principles. The lack of snow cover during the winter months is one of the consequences of climate change, which prevents the normal operation and functioning of ski resorts compared to the previous years. Examples in Europe are ski resorts in Switzerland, which are located at an altitude of less than $1800 \mathrm{~m}$, or parts of ski resorts at high altitudes, but which also have ski slopes at lower altitudes. Possible solutions are mainly making artificial snow, certain alternatives to skiing, subsidies for ski resorts, and the like. Making artificial snow may be a temporary solution, but in the long run, this solution will not be sustainable because large amounts of resources (e.g. electricity) are used to produce snow. Furthermore, the countries of the Alpine Convention face the problem of mass tourism and at one point they resolved that problem with alternative modes of transport. This means a ban on one's own vehicle in certain areas in order not to disturb the ecosystem, i.e. the functioning of flora and fauna. Ski resorts in the Italian Dolomites have tried to establish various sustainable strategies to strengthen the offer of winter activities but in a sustainable way. These are strategies such as building a ski centre that will provide high technological performance, investing in Nordic skiing and skiing off-piste, but also strategies that regulate and promote activities away from snow. Also, there are various regulations, charters in European ski resorts that represent ecological practices and ecological behaviour, such as the Cortina charter in the eponymous ski resort in Italy, France $\mathrm{CO} 2$ emissions are regulated through the Atmospheric Protection Plan and the Territorial Plan of Energy Clusters. Zermatt in Switzerland does not allow access to ski resorts except in exceptional cases and which, like the Saas-Fee ski resort (Switzerland), have the character of an energy city (Energiestadt). The Alpine Convention allows frameworks for sustainable practices to be regulated by local and regional development plans so that regions and provinces in Italy can make their own rules for land management during construction. At the European level, there is a framework called Environmental Impact Assessment and it has been implemented in national legislation.

One way to analyse environmental awareness among ski resort managers and visitors is through interviews. The interview technique was used in Utah ski resorts in the United States. Respondents believe that environmental practices are important for development of ski resorts and to help and enrich the tourist offer. They also state that they implement sustainable tourism practices, but that they have certain financial difficulties. Although they face these problems, they will continue to implement sustainable practices and cooperate more with other partners. Contrary to these views, skiers do not consider sustainable practices important for the future development and operation of ski resorts, and for them, implementation of sustainable practices is not one of the factors when choosing a ski resort. 
Transport is listed as one of the factors that harm the environment, meaning the transport of tourists to a particular place. The Blue Mountain Ski Resort in Ontario has installed CarChip technology to track vehicles belonging to managers and all other businesspeople at the ski resort. Cars, fuel consumption, and $\mathrm{CO} 2$ emissions were analysed. Drivers who participated in the research had previously had training on environmental driving. The result of the research showed that 55 vehicles at idle consume more than 42,000 1 of fuel and emit more than 97 tons of $\mathrm{CO} 2$. After the training, the results of fuel consumption and $\mathrm{CO} 2$ emissions were reduced by $8 \%$. Therefore, tourist transport can be regulated in an acceptable way considering environment protection and implementation of sustainable tourism practices.

In Queenstown, New Zealand, ski resort managers, stakeholders, and the population were interviewed about sustainable tourism business strategies. They agreed that they can respond to climate change in two ways, by exploiting the increased vulnerability of the ski industry and making artificial snow, which is the case with most ski resorts in the world and Europe. In New Zealand, the authors also researched people's attitudes towards transport in ski resorts, the existence of "green fatigue" among skiers, and how communication strategies with the environment are implemented. The results showed that people were not largely aware of climate change, but that the environment was changing over the years. Also, they have not experienced much "green fatigue" because the state sufficiently promotes sustainable practices. Most agree that ski areas need to be expanded to have more quality facilities and infrastructure.

\section{CONCLUSION}

Ski resorts face the same problems. Primarily, length of the winter season is reduced due to warmer days and insufficient rainfall caused by climate changes. That is why most ski resorts resort to strategies for making artificial snow. Especially ski resorts located at lower altitudes (below $1500 \mathrm{~m}$ ), while skiing resorts above $1500 \mathrm{~m}$ above sea level still do not have major problems with lack of snow. Making artificial snow is useful for those who manage ski resorts, but over time, this practice can reduce the number of available resources such as water and electricity, without which making snow would be impossible. Ski resort managers should already be thinking about future strategies. Some ski resorts supplement the lack of winter season with activities during the summer season or other months when there is no snowfall and thus enable the economic sustainability of the resort. This is very important because tourists have facilities on the mountain throughout the year, so it is possible to keep them longer and meet the expectations they have.

Transport to the mountains and in the mountains is one of the problems faced by ski resorts. Many are trying to reduce transportation on the mountain by organizing group transportation via buses, trains, and other means of transportation. There are also ski resorts that have banned the entry of vehicles that use fossil fuels for propulsion and transportation is only possible with electric vehicles. In this way, $\mathrm{CO} 2$ emissions are reduced, which causes great damage to nature. The problem with transport is bigger in ski resorts that face mass tourism, and then it is difficult to control it. Creating an offer that will not cause dissatisfaction due to the impossibility of its own transportation for tourists is the task of all ski resort managers.

Impacts on land through the construction of roads and infrastructure also negatively affect the ecosystem and disrupt its normal functioning. With the development of ski resorts, the need to build more increases, forests are being cleared for the construction of roads and ski slopes. All this disturbs the normal life of the plant and animal world. Certain permits are required for construction, especially in protected mountain areas. Laws and regulations control construction, but as more are built and nature changes, so will laws have to be stricter and adapted to future predictions for the environment and climate change.

For these measures to be successful to the greatest possible extent, the cooperation of the government, local bodies, ski resort managers, other tourist participants in creating an offer for tourists, the local population, and, of course, tourists are needed. Marketing strategies that will raise awareness among tourists can help concrete strategies for sustainable tourism development in ski resorts. The ski industry depends on natural conditions, and therefore there is no other way to deal with climate change than to adapt through sustainable strategies. This task is not easy because it requires a lot of knowledge, foresight, continuous cooperation, and financial resources. If ski resort managers are aware of the situation in which they find themselves, they should try to protect the environment in every possible way, as this will facilitate the implementation of climate change adaptation strategies. 


\section{REFERENCES}

Arge Alp. (2015). Scheda presentazione progetti: Cabinovia bifune Siusi-Alpe di Siusi come mezzo di trasporto alternativo da Siusi all'Alpe di Siusi (Italian). Retrieved May 14, 2020, from: https://www.argealp.org/ fileadmin/user_upload/Trentino/Projekte/italiano/Broschuere_Best_practices_in_den_alpinen_Skigebieten_it.pdf

Astat info. (2015). Turismo in Alto Adige. Retrieved May 14, 2020, from: https://www.slideshare.net/blozdicadore/anno-turistico-20152016-in-alto-adige-dati-astat

Bonzanigo, L., Giupponi C., \& Balbi, S. (2016). Sustainable tourism planning and climate change adaptation in the Alps: a case study of winter tourism in mountain communities in the Dolomites. Journal of Sustainable Tourism, 24 (4), 637-652.

Buckley, R. (2012). Sustainable tourism: Research and reality. Annals of Tourism Research, 39 (2), 528-546.

Bürki, R., Elsasser, H., \& Abegg, B. (2003). Climate Change - Impacts on the Tourism Industry in Mountain Areas. In First International Conference on Climate Change and Tourism, 9-11 April 2003. Djerba, Tunisia.

Call, A. (2012). Sustainable Ski Resorts in the State of Utah: Working Toward the Future, Utah State University, MSc thesis.

Claver-Cortés, E., Molina-Azorín, J. F., Pereira-Moliner, J., \& López-Gamero, M. D. (2007). Environmental strategies and their impact on hotel performance. Journal of Sustainable Tourism, 15 (6), 663-679.

Ecological Tourism in Europe - ETE. (2005). Sustainable Tourism Development in UNESCO Designated Sites in South-Eastern Europe. Retrieved May 12, 2020, from: http://portal.unesco.org/en/files/45338/124178725 79Introduction_Sustainable_Tourism.pdf/Introduction_Sustainable_Tourism.pdf

Epstein, M. J. (1996). Measuring corporate environmental performance: Best practices for cost and managing an effective environmental strategy. Chicago, IL: Irwin.

Giupponi, C., Sgobbi, A., Mysiak, J., Camera, R., \& Fassio, A. (2006). NetSyMoD: An integrated approach for water resources management. In: P. Maire, M. Coenen, C. Lombardo, M. Robba, \& R. Sacile (Eds.), Integrated water management: Practical experiences and case studies. Berlin: Springer.

Gössling, S., Hall, C. M., Ekstrom, F., Engeset, A. B., \& Aall, C. (2012). Transition management: A tool for implementing sustainable tourism scenarios? Journal of Sustainable Tourism, 20 (6), 899-916.

Hall, C. M. (2011). Policy learning and policy failure in sustainable tourism governance: From first and second to third order change? Journal of Sustainable Tourism, 19 (3-4), 649-671.

Hopkins, D. (2014). The sustainability of climate change adaptation strategies in New Zealand's ski industry: a range of stakeholder perceptions. Journal of Sustainable Tourism, 22 (1), 107-126. DOI: $10.1080 / 09669582.2013 .804830$.

Kassinis, G. I., \& Soteriou, A. C. (2003). Greening the service profit chain: The impact of environmental management practices. Production and Operations Management, 12 (3), 386-403.

McDonough, W., \& Braungart, M. (2002). Cradle to cradle: Remaking the way we make things. New York, NY: North Point.

Peeters, P. (2012). A clear path towards sustainable mass tourism? Rejoinder to the paper "Organic, incremental and induced paths to sustainable mass tourism convergence" by David B. Weaver. Tourism Management, 33 (5), 1038-1041.

Peeters, P. M., \& Dubois, G. (2010). Tourism travel under climate change mitigation constraints. Journal of Transport Geography, 18: 447-457.

Rutty, M., Matthews, L., Scott, D., \& Del Matto, T. (2014). Using vehicle monitoring technology and eco-driver training to reduce fuel use and emissions in tourism: a ski resort case study. Journal of Sustainable Tourism, 22 (5): $787-800$.

Scott, D. (2011). Why sustainable tourism must address climate change. Journal of Sustainable Tourism, 19(1), 17-34.

Scott, D., Peeters, P., \& Gössling, S. (2010). Can tourism deliver its "aspirational" greenhouse gas emission reduction targets? Journal of Sustainable Tourism, 18 (3), 393-408.

Scuttari, A., Volgger, M., \& Pechlaner, H. (2016). Transition management towards sustainable mobility in Alpine destinations: realities and realpolitik in Italy's South Tyrol region. Journal of Sustainable Tourism, 24 (3), 463-483. DOI: 10.1080/09669582.2015.1136634.

Smerecnik, K. R., \& Andersen, P. A. (2011). The diffusion of environmental sustainability innovations in North American hotels and ski resorts. Journal of Sustainable Tourism, 19 (2), 171-196.

DOI: 10.1080/09669582.2010.517316. 
Spector, S. (2017). Environmental communications in New Zealand's skiing industry: building social legitimacy without addressing non-local transport. Journal of Sport and Tourism, 21 (3), 159-177.

UNWTO, https://www.unwto.org/

Weaver, D. (2009). Reflections on sustainable tourism and paradigm change. In: S. Gössling, C. M. Hall, \& D. Weaver (Eds.), Sustainable tourism futures (pp. 33-40). New York: Routledge.

Working Group Sustainable Tourism of the Alpine Convention (2016-2018). Directions for Innovation in Alpine Tourist Destinations. Towards Innovative Tourist Strategies in Alpine Sites, 2019. Retrieved May 3, 2020, from: https://www.alpconv.org/fileadmin/user_upload/fotos/Banner/Topics/tourism/VI_Report_Innovation_Tourism_FINAL.pdf

Working Group Sustainable Tourism of the Alpine Convention (2016-2018). Good... in practice Alpine destinations for sustainable tourism, A Collection of Sustainable Alpine Destinations on a Path to Sustainability and Innovation in Tourist Offer, 2019. Retrieved May 3, 2020, from: https://www.alpconv.org/fileadmin/ user_upload/fotos/Banner/Topics/tourism/V_Brochure_Destinations_FINAL.pdf 